Climatic Change, 2005, v71, 9-41. DOI: 10.1007/s10584-005-5927-y

Running title: Regional integrated assessment in the UK: I. Methodology

\title{
A regional, multi-sectoral and integrated assessment of the impacts of climate and socio-economic change in the UK: Part I. Methodology
}

I.P. Holman ${ }^{1}$, M.D.A. Rounsevell ${ }^{2}$, S. Shackley ${ }^{3}$, P.A. Harrison ${ }^{4}$, R.J. Nicholls ${ }^{5}$, P.M. Berry ${ }^{4}$ and E. Audsley $^{6}$

${ }^{1}$ Institute of Water \& Environment, Cranfield University, UK

${ }^{2}$ Université catholique de Louvain, Belgium

${ }^{3}$ Tyndall Centre for Climate Change Research, University of Manchester, UK

${ }^{4}$ Environmental Change Institute, University of Oxford, UK

${ }^{5}$ School of Civil Engineering and the Environment, University of Southampton, UK

${ }^{6}$ Silsoe Research Institute, UK

Corresponding author: I.P. Holman

Cranfield University

Silsoe

Bedford MK45 4DT

United Kingdom

Tel: $\quad+44(0) 1525863000$

Fax: $\quad+44(0) 1525863344$

Email: i.holman@cranfield.ac.uk

\begin{abstract}
Policy makers and stakeholders are increasingly demanding impact assessments which produce policy-relevant guidance on the local impacts of global climate change. The 'Regional Climate Change Impact and Response Studies in East Anglia and North West England' (RegIS) study developed a methodology for stakeholder-led, regional climate change impact assessment that explicitly evaluated local and regional (sub-national) scale impacts and adaptation options, and cross-
\end{abstract}


sectoral interactions between four major sectors driving landscape change (agriculture, biodiversity, coasts and floodplains and water resources). The 'Drivers-Pressure-State-Impact-Response' (DPSIR) approach provided a structure for linking the modelling and scenario techniques. A $5 \mathrm{~km}$ x $5 \mathrm{~km}$ grid was chosen for numerical modelling input (climate and socio-economic scenarios) and output, as a compromise between the climate scenario resolution $(10 \mathrm{~km} \mathrm{x} 10 \mathrm{~km})$ and the detailed spatial resolution output desired by stakeholders. Fundamental methodological issues have been raised by RegIS which reflect the difficulty of multi-sectoral modelling studies at local scales. In particular, the role of scenarios, error propagation in linked models, model validity, transparency and transportability as well as the use of integrated assessment to evaluate adaptation options to climate change are examined. Integrated assessments will provide new insights which will compliment those derived by more detailed sectoral assessments.

\section{[Word count $=199$. Maximum allowed $=200$ words $]$}

\section{Introduction}

There is growing acceptance that the climate is changing due to human emissions of greenhouse gases (IPCC 2001a). Such changes in climate will affect all sectors of society at different scales, ranging from the global to the local. It is also recognised that significant socio-economic and political changes will also continue to occur (IPCC, 1996; Nakicenovic and Swart, 2000) and the impact of climate change needs to be evaluated in a holistic assessment of the effects of our changing future.

Research strategies have been reported on the impacts of climate change on specific sectors (e.g. agriculture: Downing et al., 2000; Abler \& Shortle, 2000; water: Arnell, 1998; Miles et al. 2000; biodiversity: Sykes and Haxeltine 1998; Leemans 1999; and coastal zones: Nicholls and Mimura, 1998; Nicholls, 2002a). These have generally involved the development, and application, of impact models to scenarios of climate change, to understand the sensitivity of specific sectors to variations in climate. Other possible (non-climate) changes have often not been considered. However, addressing policy questions requires integrated analysis, including the effects of all change factors, the interactions between sectors and an evaluation of adaptation options for individual stakeholders at the local and regional scale (Cash and Moser, 2000). This is because the actual impacts of climate change locally or regionally will be the product of multiple interacting systems. This requires the paradigm of climate change impacts' assessment to shift in focus:

- from presenting potential (usually worst-case) impacts to analysing different adaptation options (e.g. Johnston \& Chiotti, 2000; Downing et al., 1997); and 
- from sectoral concerns to integrated assessments of landscapes and economies (e.g. Handmer et al., 1999; Smit et al., 2001; Fisher, 2000).

Integrated assessment (IA) has been defined by the Intergovernmental Panel on Climate Change as "an interdisciplinary process that combines, interprets, and communicates knowledge from diverse scientific disciplines from the natural and social sciences to investigate and understand causal relationships within and between complicated systems" (IPCC, 2001b). It is axiomatic that there are two main principles to integrated assessment: (1) integration over a range of relevant disciplines; and (2) the provision of new information about how complex real-world systems might behave that enables decision making (Harremoes and Turner, 2001). Importantly, cross-sectoral implications that might be missed in more traditional assessments can be explicitly explored in ways that are meaningful to relevant stakeholders. Although there are papers describing the theory of integrated assessment (for example Jones, 2001; Harremoes \& Turner, 2001; Warren, 2002), there are few studies which describe the results of such an assessment at the regional (sub-national) scale (e.g.; Rosenberg 1993, Yarnal, 1998; Yohe et al. 1999, 2002, Fisher, 2000; Strzepek et al. 2001) as opposed to the supra-national and global scales (e.g. Dowlatabadi, 1995; Nordhaus and Yang, 1996; Alcamo et al., 1998; Parry et al., 1999; Tyson et al. 2001; Matsuoka et al., 2001; Toth, 2003).

This paper describes the first such local to regional (sub-national) scale study in the UK - 'Regional Climate Change Impact and Response Studies in East Anglia and North West England' (RegIS) (Holman and Loveland, 2001; Holman et al., 2001). RegIS aimed to develop a research methodology for stakeholder-led, regional climate change impact assessment that explicitly evaluated local and regional scale impacts and adaptation options, and cross-sectoral interactions between the major sectors driving landscape change. Stakeholders had previously raised concerns about environmental change impacts on agriculture, biodiversity, coasts and floodplains and water resources in the study areas (Science and Policy Associates \& ESYS, 1996). These 'sectors' formed, therefore, the basis for the RegIS integrated assessment. The emphasis of this paper is on (1) the integrated methodology that was developed to deliver a fine resolution multi-sectoral assessment and (2) the lessons learned about conducting local and regional (sub-national) scale integrated assessment with regionally-specific socio-economic and climate scenarios and linked sectoral models. The results of the assessment are presented in Part II (Holman et al. Submitted).

\section{Methodology}

The development of the RegIS integrated assessment methodology (IAM) was guided by a number of fundamental principles. Firstly, the methodology should be transportable to other areas. Although 
two contrasting regions were studied which provided good 'test-beds' for the diversity of the problems and approaches to be examined, a generic framework for linking knowledge was needed. Secondly, stakeholders should be involved throughout the study contributing to the design and use of the IAM through an Interactive Integrated Assessment Process (IIAP) (Warren, 2002). This interaction and feedback ensures the acceptability and applicability of IAM in the policy arena and maximises the usefulness of IA. Stakeholder representation should encompass national (NGOs, private sector and central government), regional (NGOs, regional bodies, councils, lobby groups) and local (individuals, local authorities, local companies and NGOs) levels (Shackley \& Deanwood, 2002). Thirdly, a modelling scale was needed that balanced the detailed spatial resolution desired by stakeholders against data and model run-time constraints that result from an integrated, multi-sectoral modelling approach. Finally, a modular approach should be used that builds upon existing impact models, where available.

\subsection{Stakeholder involvement}

A fundamental objective of RegIS was to involve stakeholders throughout the study, from inception, through design, implementation and management, to the delivery of the project results. This was achieved in a number of ways:

- The sectors studied in RegIS (agriculture, biodiversity, coast and floodplains and water resources) were dictated by earlier stakeholder analysis (Science and Policy Associates \& ESYS, 1996), and were not chosen by the research team. The domains of impact were therefore not dictated by the tools available to the research team, but rather the research team was chosen to deliver the desired tools;

- A stakeholder group (United Kingdom Water Industries Research- UKWIR, representing the water supply and wastewater treatment utilities) part-funded the project;

- The project was undertaken under the auspices of the United Kingdom Climate Impacts Programme (UKCIP) who provide support and guidance for climate impacts research for both stakeholders and researchers, so providing a bridge between the researchers and the decisionmakers in government organisations and business;

- The project was guided by the RegIS Steering Committee which included representatives of national Government, the Environment Agency (national environmental regulator), English Nature (ecological conservation Government Agency), UKWIR and UKCIP;

- Within the pre-defined domains of impact, three regional workshops involving about 100 participants (as described in Shackley and Deanwood 2002) were used to engage the stakeholders in the design of the integrated assessment modelling, by providing their priority questions and problems for the scientific team to address, and by identifying possible response mechanisms; 
- The regionalization of the national socio-economic storylines were undertaken through an iterative process with local and regional stakeholders using individual interviews (about 35) and the three regional workshops;

- Stakeholders were involved in the development and critique of the spatial quantitative pressures either directly (through face-to-face discussion) or indirectly (through the incorporation of published consultative plans such as regional strategies, structure plans and shoreline management plans);

- Regional and national stakeholders (conservation agencies and NGOs) were actively involved in the selection of target habitats and the species modelled;

- Non-technical workshops were held to review preliminary proposals for major milestones such as the IA framework;

- A technical workshop for stakeholders was held at the end of the project to discuss the project results and to reflect on the lessons learnt;

- A non-technical summary report of the outputs of the project was published to aid wider dissemination of the project results (Holman et al., 2001);

- The project results were widely presented at stakeholder events (in addition to academic conferences) both within the regions and nationally.

\subsection{The generic framework}

The assessment framework was based on the 'Drivers-Pressure-State-Impact-Response' (DPSIR) approach (Figure 1) proposed by the Organization of Economic Co-operation and Development (1993) and used extensively by the European Environment Agency (1998) and the UK Environment Agency. The DPSIR framework allowed the RegIS methodology to be built around a consistent structure of linked assessments (Peirce, 1998), that facilitates the use of the approach in other regions. The components of the DPSIR analytical framework were used to define the various stages of the RegIS methodology:

D: Drivers are the underlying exogenous (to the region) causes of environmental change, e.g. climate and socio-economic change, national and international (EU) policy.

- Methodological approach = identify and describe (qualitative narratives or storylines) national and international scenarios of change, which are linked to the pressure variables and indicators used for model input.

P: $\quad$ Pressures are the endogenous (to the region) variables that quantify the drivers, e.g. temperature, precipitation, carbon dioxide concentrations and extreme climatic events for climate 
change; and population, GDP, regional development, national and EU subsidies, environmental and regulatory policies for socio-economic change.

- $\quad$ Methodological approach = develop regional, quantitative scenarios of climate and socioeconomic change; estimate confidence in assumptions and quantification.

S: $\quad$ States are the variables (indicators) that represent the sensitivity of the system/sector to the pressure variables, e.g. river flows, land use areas, species suitability.

- Methodological approach = identify critical indicators for sectoral impacts and cross-sectoral interactions with stakeholders; identify sensitivity of impacts and interactions using historic analogues, e.g. previous droughts, changes in crop subsidies, increases in housing stock.

I: $\quad$ Impacts are a measure of whether the state variables have reached a certain value (represented by thresholds, classes, etc.), which has a negative or positive effect on individuals, society and/or biological resources, e.g. minimum levels of river flows, acceptable farm profit, minimum species richness, etc.

- $\quad$ Methodological approach = develop an integrated database; adapt existing models; draw upon expert knowledge; integrate models and expert knowledge across sectors with consistent linkages; develop indicator thresholds.

R: Responses are the planned (societal level) adaptation options that aim to minimise negative impacts (or maximise positive impacts / benefits)

- $\quad$ Methodological approach = identify adaptation options with stakeholders; evaluate options with linked models and expert knowledge.

The RegIS methodology is illustrated in Figure 2. The drivers and pressures were defined in terms of scenarios of environmental change, integrating both climate and socio-economic change. State variables, and impacts were assessed using a range of coupled, sectoral models. The linkages between the different sectoral components are described later. The results of these models were evaluated in terms of potential policy responses based on stakeholder dialogue within the context of the socio-economic scenario assumptions.

Although the DPSIR framework is based on a sequential approach, elements within an integrated system can play multiple roles within the framework. For example, changes in crop and land use distribution may represent an 'impact' for the agricultural community, but may also be a 'pressure' on water resources and biodiversity. In working within the DPSIR framework, therefore, the RegIS integrated methodology follows a quasi-sequential approach to the flow and interpretation of information. 


\subsection{The case study regions and the modelling scale}

Two contrasting regions were studied (Figure 3): East Anglia with its relatively dry climate (average annual rainfall $=550-750 \mathrm{~mm}$ ), low-lying topography and intensive agriculture, and the North West with a wet climate (average annual rainfall $=650-3200 \mathrm{~mm}$ ), uplands dominated by extensive grazing and urbanised lowlands. RegIS sought to accommodate the heterogeneity of the study regions by applying a spatially-explicit modelling approach. In order to achieve this, and to accommodate the flow of information between different sectoral models, a common representation of geographic space was required.

A detailed spatial resolution (of the order $1 \mathrm{~km} \times 1 \mathrm{~km}$ ) was desired by stakeholders. However, certain types of input data (for example, observed species distributions, standards of protection for flood defences) were not available at such detailed resolution. Further, the most up-to-date climate scenarios (described below) available from the United Kingdom Climate Impacts Programme (UKCIP) were provided at a resolution of $10 \mathrm{~km} \times 10 \mathrm{~km}$. These scenarios were generated by interpolating GCMscale changes to a finer resolution using a standard spatial filter and then adding these interpolated changes to observed mean monthly climatologies. This approach is termed 'unintelligent downscaling' (Hulme \& Jenkins 1998) because it adds no new meteorological insight beyond the GCM-based changes into the interpolation procedure, and hence implicitly limits the credibility of much further downscaling. Thus, as a compromise, a geographic grid of $5 \mathrm{~km} \times 5 \mathrm{~km}$ was chosen for both data input and, where appropriate, model output except for the hydrological modelling where catchments and water resource units were also used. This ensured that stakeholders were presented with information that was of sufficient detail for use in regional decision support, whilst limiting misuse or over-interpretation of model results as very local scales.

\subsection{Input Scenarios}

\subsubsection{Climate scenarios}

The study applied climate change scenarios developed on behalf of the United Kingdom Climate Impacts Programme (UKCIP), known as the UKCIP98 scenarios (Hulme and Jenkins, 1998). These scenarios are based on two transient experiments undertaken at the UK Hadley Centre for Climate Prediction and Research using the HadCM2 GCM (Johns et al., 1997; Mitchell and Johns, 1997). The two experiments are GGa (1\% p.a. increase in greenhouse gases - approximates to the IS92a emissions scenario) and GGd (0.5\% p.a. increase in greenhouse gases - approximates to the IS92d 
emissions scenario). The IS92 emissions scenarios (Leggett et al. 1992) were used by the Hadley Centre as the UKCIP98 scenarios rely largely on one set of GCM experiments completed during 1995 and 1996 (Hulme \& Jenkins 1998), prior to the development of the SRES (Nakicenovic \& Swart 2000) scenarios.

Four scenarios were constructed from the two HadCM2 experiments to reflect uncertainties in future global warming rates attributable to different climate sensitivities and greenhouse gas emissions scenarios: Low, Medium-low, Medium-high and High. The Medium-low and Medium-high scenarios were based directly on the GGd and GGa experiments, respectively. The Low scenario was based on scaling the GGd experiment with a low climate sensitivity $\left(1.5^{\circ} \mathrm{C}\right)$, whilst the High scenario was based on scaling the GGa experiment with a high climate sensitivity of $4.5^{\circ} \mathrm{C}$. Probabilities can not be attached to the four scenarios, rather the Medium-low and Medium-high scenarios can be considered as equally likely and the Low and High scenarios may be seen as capturing part of the tails of the distribution of possible climate outcomes for the UK (Hulme and Jenkins, 1998). Each scenario has been constructed for three time periods (the 2020s, 2050s and 2080s) based on an average of 30 years of data at a $10 \mathrm{~km} \times 10 \mathrm{~km}$ spatial resolution. Data for each $10 \mathrm{~km} \times 10 \mathrm{~km}$ grid square were translated into the desired $5 \mathrm{~km} \times 5 \mathrm{~km}$ spatial resolution using the altitude adjustments presented in Smith (1976). The long-term monthly means in each grid square were downscaled to daily time series of 30 years of weather data by perturbing observed daily weather station data by the UKCIP98 change fields, thereby ensuring that the generated sequences, correlations and extremes are plausible.

\subsubsection{Socio-economic scenarios}

The widespread practice of studying the impacts of future climate changes as if they were imposed in today's society may be acceptable for near-term assessments but grows increasingly unacceptable as the time horizon lengthens (Parson and Granger Morgan, 2001; Arnell et al., 2004). The future world will be very different from now even in the absence of climate change because of socio-economic and political changes. Scenarios, which should contain everything that shapes a society (Tol 1998), aim to be coherent, internally consistent and plausible descriptions of these possible future states which can be used to inform future trends, potential decisions or consequences (Carter et al., 1994; Parry and Carter, 1998). However, our lack of fundamental understanding of the processes determining socioeconomic change dictates that multiple scenarios representing a plausible range of alternative futures are needed, to explicitly acknowledge the inherent uncertainty in such projections.

The development of plausible socio-economic scenarios to couple with climate scenarios, which include enough regional detail and explicit acknowledgment of uncertainties but avoid the combinatorial explosion of crossing many independent uncertainties, is one of the central methodological difficulties of integrated regional impact assessment. Such scenarios help to open up 
the uncertainty of the decision making context to scrutiny by stakeholders and policy makers, yet they greatly limit the exploration of uncertainty to a discrete (usually small) number of possibilities. Whilst pragmatic considerations dictate such constrained uncertainty, it is important that the heuristics employed are transparent.

In a regional study, particularly one in which contrasting regions are being studied, international (Nakicenovic and Swart, 2000) and national (UKCIP, 2001)-scale socio-economic scenarios cannot be used directly, but have to be modified such that they discriminate between and within regions. The RegIS socio-economic scenarios used the framework (Figure 4) of Berkhout et al. (2002) as a starting point which had been adopted for the UKCIP national socio-economic scenarios (UKCIP 2001). This scenario framework segments the future 'possibility space' into four quadrants that are defined by axes of social and political 'values' and 'governance' and the capacity of institutions at different levels to manage change, but which in turn had been adapted from the IPCC's SRES framework. The relationship between the national (UKCIP) and regional (RegIS) socio-economic scenarios mirrors to some extent the two-tracked approach of centralised and decentralised scenario development used in the US National Assessment (Parsons and Granger Morgan 2001). The socio-economic scenarios had two distinct roles in RegIS, which were to provide the context (storylines) for interpreting the results of the numerical modelling and to provide quantitative inputs to the land use, coastal and floodplain and hydrology models.

The regional socio-economic scenarios developed in RegIS (Shackley \& Deanwood, 2003) were derived from an iterative procedure between researchers and stakeholders with interests in the sectors under consideration at national, regional and local levels. In accordance with the preferences of the RegIS funders and the UKCIP, formally independent socio-economic scenarios were developed, also referred to as 'non-climate change' scenarios, as they do not permit interaction between climate and socio-economic changes, such as occurs in co-evolutionary socio-economic scenarios (Lorenzoni et al., 2000). The development of non-climate change scenarios demands an approach which attempts to embrace complex societal and economic change and uses these as indicators of plausible future states. Thus they do not emerge directly from current practises per se, rather they abstract particular forces for change, differentiating and extrapolating them.

The regional descriptive storylines of alternative futures are broadly similar to the related national (Berkhout et al. 2002) and global narratives (Nakicenovic and Swart, 2000; Arnell et al., 2004). In addition to the aforementioned sources, the construction of the RegIS scenarios drew upon three regional workshops involving approximately 100 regional and sub-regional stakeholders from the public, private and voluntary sectors, existing medium-term plans (structure plans, regional planning guidance and regional economic strategies), and numerous face-to-face meetings with key regional 
stakeholders. Each storyline provided a general contextual description and a more detailed elaboration of the regional economy, society and environment.

These qualitative storylines had to be further developed so as to provide the inputs to sectoral models, which require quantitative, regionally-specific data for those variables which are dependent upon future socio-economic change and policy dimensions. It was necessary, therefore, to derive a range of numerical parameters based on the input requirements of the RegIS sectoral models (Table 1; Figure 5). Some of these parameters do not vary in space across a region, (e.g. prices for agricultural goods), whereas others are strongly driven by location characteristics (e.g. population, land use planning) and so were allocated values that varied spatially. However, the lack of parameter ranges provided by the national scenarios (for example, for population, household numbers etc.) within the constrained uncertainty of the segmented futures, prevented the explicit quantification of judgements about uncertainty. A detailed description of the derivation of the spatial variables for urbanization and nonspatial variables for agriculture is given by Shackley and Deanwood (2003).

\subsubsection{Scenario linkage}

One of the difficulties in integrated assessment is the large number of scenario combinations (of climate and socio-economic change) which are possible between regions, time-slices and storylines, and the significant run-time constraints associated with integrated models. Therefore, RegIS developed two contrasting regional scenarios that coupled assumptions about changes in socioeconomic futures to climate change following Lorenzoni et al. (2000) and Rounsevell (2000). The climate and socio-economic change scenarios were linked through their associated carbon dioxide emission assumptions, to generate futures in which the degree of socio-economic development was broadly consistent with the climate change.

The chosen contrasting futures for the modelling were:

- A Regional Enterprise socio-economic scenario (equivalent to IPCC A2) linked with the UKCIP98 High climate scenario (constructed from the HadCM2 GGa experiment scaled to the IS92a emissions scenario and a high climate sensitivity of $4.5^{\circ} \mathrm{C}$ );

- A Global Sustainability socio-economic scenario (equivalent to IPCC B1) linked with the UKCIP98 Low climate scenario (constructed from the HadCM2 GGd experiment scaled to the IS92d emissions scenario and a low climate sensitivity of $1.5^{\circ} \mathrm{C}$ ).

The former represents a high climate change scenario combined with the socio-economic scenario which is likely to impose the highest socio-economic pressure upon water, agriculture, coastal / floodplain area and biodiversity. As the socio-economic scenarios contain no element of the climate 
change scenarios, this provides an extreme case of a society that does not respond to the threat of climate change over the next 50 years, i.e. an 'adverse case' analysis.

The lowest climate change scenario is combined with the socio-economic scenario which brings with it the lowest pressure upon water, biodiversity, agriculture and coastal/flood plain areas, i.e. a 'better case' analysis with respect to pressures upon environmental systems and associated impacts. The selection of these scenario combinations (in the context of resource constraints) was agreed upon with the active participation of the stakeholders.

In addition, the linked models were run for the two climate change scenarios with baseline socioeconomics to assess the relative importance of climate change compared with socio-economic change. The 2050s time slice was chosen for the integrated assessment, because of the limited changes associated with the 2020s time slice (within both climate and socio-economic scenarios) and because of issues of credibility associated with deriving detailed socio-economic scenarios for as far ahead as the 2080s.

It is acknowledged that the linking of the climate and socio-economic change scenarios through their associated carbon dioxide emission assumptions to create internally consistent futures is subjective. The socio-economic change scenarios embody local practices whilst the climate scenarios reflect global emissions, which in turn can arise from multiple disparate socio-economic states throughout the globe. However, the underlying intention was to develop two contrasting regional futures which, by being internally consistent, did not contain explicit inconsistencies which would render the subsequent analyses suspect in the eyes of some stakeholders.

\subsection{Sectoral impact models}

\subsubsection{Coasts and floodplains}

The coastal and river flooding analysis combined a series of algorithms (Nicholls and Wilson, 2001; Nicholls, 2002b) to assess the impact of: sea-level rise on coastal flooding and hence the agricultural sector; increased river flooding on the agricultural sector; and sea level rise on coastal habitats.

The effect of sea level rise on tide-surge heights was estimated by adding the UKCIP98 sea level rise projections to the water levels of specific return periods. However, the scenarios provide no data for other climatic factors such as storminess. No sign of a significant increase in storminess over NorthWest Europe was detected from an analysis of long-term observational sea level data sets (Bijl et al. 1999). The weak changes in storm activity and (extreme) wave heights in the northeast Atlantic and 
North Sea and a weak increase in storm surges in the southern and eastern part of the North Sea simulated with $\mathrm{CO}_{2}$ doubling by Carretero et al. (1998) fall well within the limits of variability observed in the past. According to Senior et al. (2002), the confidence in all AOGCM results for storminess is limited by poor spatial resolution in global coupled models and by uncertainties in the physical processes in both global and regional models, and is specific to the climate change scenario used. An analysis of climate indices derived from HadCM2 output by Hulme \& Jenkins (1998) suggests that although overall winter gale frequency may decline under the Medium-High scenario in the future, very severe winter gales increase. However, the changing direction of change between the 2020s, 2050s and 2080s indicates that a clear anthropogenic signal in severe gale frequencies is not easily detectable in model output from the noise of natural climate variability. On this basis, these other factors were therefore assumed to remain constant.

Coastal flood plains where the future standard of defence (i.e. risk of flooding) will be at, or below, a specified level were identified from national data sets, such as the Sea Defence Survey and the Indicative Flood Plain Maps. Based upon an analysis of observations of farmers' behaviour and the opinions of agricultural advisors, it is suggested that there are specific thresholds of flooding frequency at which different types of farming activity are abandoned (Morris, 2003). Flood plains with a future defence standard of less than 1 in 10 years were therefore assumed to be unsuitable for arable farming within the agricultural sector modelling, while those with a future defence standard of less than 1 in 1 year were assumed to be unsuitable for both arable and pastoral farming.

The fluvial flood risk assessment assumed a spatially uniform increase in the 1 in 100 year flood flows of $5 \%$ and $20 \%$ for the 2050s Low and High scenarios, respectively, following the model results of Reynard et al. (2001). However, due to a lack of readily available data on either the location or the standard of fluvial defences the present risk of flooding was estimated by using Indicative Standards of Protection for Fluvial Defences (Ministry of Agriculture, Fisheries and Food, 1999) and the actual land use (arable, pastoral or semi-natural). For example, it would be expected that, according to MAFF (1999), high density urban areas prone to flooding would have flood defences installed which have a capacity to protect the area from a 1 in 100 year (or 1\% probability) flood event, whilst low productivity agricultural land with few properties at risk would only be protected to withstand a 1 in 1 year flood event.

Coastal lowlands are particularly vulnerable to flooding, as there is the potential interaction of higher peak river flows, higher sea levels and (usually) localised subsidence. In the coastal lowlands such as the Norfolk Broads, the Lancashire coastal plain, and most particularly the Fens, land drainage and subsequent consolidation, oxidation and loss of peat has produced substantial declines in land elevation. This is illustrated by the $4 \mathrm{~m}$ decline in land levels at Holme Fen Post in the Fens since the 
1851. Today, most of the Fens lie at elevations below high tide levels and some areas are below mean sea level. In these agriculturally productive areas, the low river gradients allow the tidal influence to extend far inland, whilst the straightening and embankment of the channels has reduced the flood storage capacity. The combined effects of increased peak river flows flowing at a higher base level due to sea-level rise was considered in coastal lowlands such as the Fens in East Anglia.

The change in flood risk suggests significant impacts on the built environment, although this was not explicitly addressed in RegIS due to resource constraints. However, region-wide estimates of the order-of-magnitude effect of climate change on flood damages were derived by applying the average change in flood risk associated with the climate change scenarios to estimates of the present level of damages (Halcrow Maritime et al., 2000). The limitations of these calculations are that:

- It is assumed that the increase in flood risk due to climate change simply results in more of the same floods, rather than more extreme events;

- No allowance is made for the increased depth and extent of flooding under climate change, which will increase the losses;

- Some properties that presently sustain flood damage might be abandoned under climate change scenarios, which might reduce the losses due to flooding;

- Uniform changes are being assumed across both regions, and the more severe impacts described for coastal lowlands such as the Fens are not resolved;

- The basic results are based on different assumptions in different regions and should be treated with caution (Halcrow Maritime et al., 2000).

The effect of sea level rise on two coastal habitats was analysed: salt marsh and coastal grazing marsh. Salt marsh losses at the morphological scale were predicted on the basis of their ability to maintain elevation relative to sea-level rise, estimated as a function of the rate of sea level rise, tidal range and changing sediment supply (Nicholls and Wilson, 2001). Landward migration of these habitats is presently prevented in most locations by coastal flood defences, but coastal management policy is investigating large-scale managed realignment of these defences in the coming decades (French, 2001). Therefore, areas of the coastal flood plain with very low development density were considered, depending upon the socio-economic scenario, as potential sites for planned managed realignment, and consequent intertidal habitat creation. The habitat gain was sub-divided between non-vegetated mudflat and salt marsh. Salt marsh gains associated with managed retreat are often at the expense of coastal grazing marsh. The likelihood of unplanned habitat creation was also considered. 


\subsubsection{Agricultural sector modelling}

An attempt to assess agricultural land use change needs to explicitly incorporate descriptions of the goals and constraints that affect farmers and their management strategies. Farmers are operating within a broadly similar economic environment (at the regional scale) but, subject to their own preferences, opinions and experiences, they are faced with considerable differences in the physical characteristics of the landscape, such as soil types and climates.

Assessments for the agriculture sector were therefore based on a spatially distributed model of agricultural land use that integrates an approach to the optimisation of farm level cropping decisions (SFRAMOD: Annetts \& Audsley 2002) with a crop growth model (ACCESS: Rounsevell et al., 1996). The approach is described in detail in Rounsevell et al. (2003). ACCESS simulates the yield response of the major arable and grass crops to the biophysical environment in each grid square (soils, climate and $\mathrm{CO}_{2}$ ). Crops include permanent crops such as grazing, perennial crops such as forage, annual crops such as wheat, rape and set-aside, 'novel' crops such as sunflowers and soya, and catch crops. It provides output on the crop dry matter yield each year, crop maturity date, nitrogen applied to the crop and, for irrigated crops, the yield with different levels of irrigation applied to the crop.

The farm level model selects the optimum steady-state farm system according to a series of constraints with an objective that is a weighted sum of the profit and a measure of risk. Constraints arise from timeliness penalties (which reduce the yield of a crop if, for example, it is planted late due to restricted workable hours or labour capacity) and rotational penalties (which reduce the yield of one crop following another, for example wheat after wheat relative to wheat after oilseed rape, due to pest and disease incidence).

Generic farms within SFARMMOD optimise their long term farm cropping plan on each soil type within each grid cell by maximising farm profit, in response to changes in the profitability/feasibility of enterprises and soil workability brought about by changes in climate and / or socio-economics. SFARMOD assumes that a generic model farm is representative of the sum of the cropping plans on that soil within its grid cell. The primary decision variable in the farm level model are the crop gross margins, but these are indirectly affected by subsidies (socio-economic scenario), nutrient inputs (inputs are increased pro-rata with yield to account for increased offtake) and restrictions (socioeconomic scenario), rotational and operations restrictions (resulting from soil-climate interactions and labour and machinery restrictions). The results are the areas of each crop and the profitable level of irrigation. The farm changes indicated by these results could be, for example, a new crop type such as soya, or a change of farming type such as rough grazing to intensive grass to arable. 


\subsubsection{Water resources modelling}

The distributed semi-empirical SWANCATCH (Surface WAter Nitrate CATCHment) model (Holman et al, 2001), developed from the SWATCATCH model (Hollis \& Brown, 1996; Brown et al 2002), was used to simulate naturalised (i.e. without the effect of human water abstraction and effluent returns) surface and gross groundwater resources and weekly river flows and nitrate concentrations. Nitrate was chosen to be modelled because of its important direct links to policy (e.g. the Nitrate Directive 91/676/EEC) and land management. SWANCATCH routes the hydrologically effective rainfall (that proportion of the rainfall which is able to runoff or recharge an underlying groundwater store) and leached nitrate through each soil type in a catchment directly to surface water or via a groundwater store, according to the hydrological pathways described by the Hydrology Of Soil Types (HOST) system (Boorman et al, 1995). The model does not estimate recharge of a 'real' aquifer, but rather recharge of a groundwater store, from which groundwater can support river flows and, where an aquifer is present, abstraction.

After simulating each sub-catchment or catchment in isolation, to determine the water and solute inputs from its directly contributing area, the inputs from upstream catchments are added together. Inriver denitrification processes, linked to temperature, residence time and flow characteristics (Holman et al, 2001), are included.

Naturalised (i.e. without the effect of human water abstraction and effluent returns) surface and gross groundwater resources were simulated for a number of reasons. Firstly, the starting point for decisions on current and future surface water abstraction licencing in England are based upon naturalized flows, in order that abstractions are not permitted on the basis of effluent returns to a catchment which might cease in the future due to sewerage network changes etc. Secondly, there are large scale local and regional water supply networks in both regions which transport abstracted surface water or groundwater from one catchment or groundwater management unit to another, or which allow water to be imported or exported from the region. Similarly sewerage networks move wastewater and stormwater between catchments. The spatial and temporal behaviour of these networks within the regions are confidential and cannot be readily incorporated within catchment scale models. Thirdly, water abstraction locations and the licence agreements attached to them change due to water quality or quantity problems and policy changes, so that the future spatial distribution of abstraction sites cannot be predicted. However, an attempt is made to combine the regional results of the naturalized simulations with the implications of regional development and population within the socio-economic scenarios. 


\subsubsection{Biodiversity modelling}

Impacts on the distribution of suitable future climate space for semi-natural species were simulated using the SPECIES (Spatial Estimator of the Climate Impacts on the Envelope of Species) model (Pearson et al, 2002). The model uses an artificial neural network to integrate bioclimatic variables for predicting the distribution of species through the characterisation of bioclimatic envelopes. A number of integrated algorithms, including a climate-hydrological process model, are used to pre-process climate (temperature, precipitation, solar radiation, vapour pressure and wind speed) and soils (available water holding capacity) data to derive relevant bioclimatic variables for input to the neural network. Those variables found to be most successful for simulating bird distributions and the distributions of other taxa are described in Harrison et al. (2003) and Berry et al. (2003), respectively.

SPECIES is trained using existing empirical data on the European distributions of species to enable the full climate space of a species to be characterised and to capture their response to climatic conditions that might be expected under future scenarios. A kriging interpolation function is applied to the presence/absence distributions of each species to provide a smoothed suitability surface. The data are then randomly divided into three groups for training, validating and testing the neural network. The validation set ensures that the network does not over-train on the training data, thus losing its ability to generalise, while the test data is used to independently verify the prediction. The Kappa statistic of similarity $(k)$, a commonly used statistic that provides a measure of proportional accuracy adjusted for chance agreement, was used to assess the predictive performance of each network (Cohen, 1960).

Once a network is trained, validated and tested at the European scale, it can then be used to produce a map of the simulated distribution for baseline (1961-90) climate and to estimate the potential redistribution of a species under alternative climate change scenarios at a finer $5 \mathrm{~km} \times 5 \mathrm{~km}$ spatial resolution in Great Britain. The model does not simulate the dispersal ability of a species and hence cannot simulate actual distributions.

SPECIES was applied to a range of dominant, sensitive and threatened species in habitats which interact with agriculture, water and coastal zones in the two case study regions (Table 2). The selection of both habitats and species was undertaken in conjunction with regional stakeholders.

\subsection{Model integration}


Figure 2 gives an overview of the modelling framework and the relationships between the different sectoral components. Within this framework a number of points of integration were developed between the sectoral models. These are detailed below:

1. Relevant spatial and non-spatial data, such as the climate change and socio-economic scenarios and baseline data, that were common to the different sectoral models were stored within a geographic information system (GIS);

2. Using data from the GIS, the coastal and river flooding models defined areas that were not suitable for pastoral and/or arable agriculture, and changes in coastal habitat areas;

3. The output from the coastal and river flooding models together with the areas of non-agricultural land use (urban and woodland) derived within the socio-economic scenarios were used to identify the land area available to agriculture. Physical restrictions, based on slope and soil thickness (stored within the GIS) and policy restrictions on land management, such as Nitrate Vulnerable Zones (given within the scenarios) were also used to limit agricultural crop and management choices. A final distribution of agricultural land use was determined by incorporating these spatial restrictions with climate, soil and economic data within the agricultural models;

4. The agricultural models provided outputs of hydrologically effective rainfall, nitrate-nitrogen available for leaching and the long term nitrate-nitrogen leached for input to the water resources modelling. Combined with average weekly temperature and spatial and attribute soil data for each catchment, the hydrological model simulated gross groundwater resource, river flows and nitrate concentrations;

5. The biodiversity model used data from the GIS to determine the potential distribution of species for selected habitats. These potential distributions were limited by changes in coastal habitats for salt marsh and coastal grazing marsh species (from the coastal modelling), changes in agricultural land use and management for upland hay meadows, lowland heathland and cereal field margin species (from the agricultural modelling), and changes in water quality and quantity for blanket and raised bog and the Fen species (from the water resources modelling).

\section{$4 \quad$ Discussion of the methodology}

Integrated assessments are increasingly important to both the scientific and policy-making community because of the need to understand complex systems and process interactions across a range of scales and sectors. The RegIS study has raised some fundamental methodological issues that reflect the general difficulties of multi-sectoral modelling studies. As the focus of this paper is the integrated assessment methodology for a regional climate impact study, the discussion is restricted to methodological lessons and issues. In particular, we examine the role of scenarios, error propagation in linked models, model validity, transparency and transportability as well as the use of integrated 
assessment to evaluate adaptation options to climate change. Results of the analysis are discussed in Part II (Holman et al. Submitted).

\subsection{Scenarios}

Scenarios are an integral part of the DPSIR framework and climate impact assessment (Leemans 1999) and are widely used by the scientific and policy-making communities. Although scenario development is an imperfect 'science' (Parson \& Granger Morgan, 2000 p4), few alternatives exist in exploring unknown futures. One of the principal limitations of scenarios results from feedbacks across scale boundaries in complex systems. An example of this in RegIS is the effect of changing land use areas on agricultural prices: increasing the local supply of an individual crop may result in lower prices dependent upon market demand and supply. These types of dynamic cross-scale processes cannot be readily dealt with in a satisfactory way using a regional scenario approach, and alternative approaches (e.g. Cash and Moser, 2000) that can operate across scales such as hierarchy theory or nested scenarios and models that operate at different scales may be needed (Easterling, 1997). For example, some studies have attempted to model the price change feedback that results from agricultural land use change using global scenarios and a model of macro (global) economics that simulates the changes that occur in every other region of the world (e.g. Parry et al., 1996; Alcamo et al., 1996; Conway et al., 1996). The limitation of these studies, however, is that the representation of global-scale processes is not always adequate (due to the complexity and variety of the world) and there is a loss of regional specification (Toth, 2003) and detail that is the aim of a 'regional study' (Easterling, 1997) such as RegIS. There are clear conflicts, therefore, in the ability to model all the processes that are important for a region, at the regional scale. This ultimately may be a fundamental limitation of a stand-alone regional approach, such as RegIS where the predetermined geographical area and constrained time and resources limited investigation of cross scale issues and processes in sufficient depth.

At a pragmatic level, there are fundamental difficulties in the construction of regional (sub-national) socio-economic scenarios, as identified by Parson et al. (2003). The development of scenarios, and in particular the stakeholder engagement and dialogue process, is time consuming. The time and resources required to develop the level of spatial dissaggregation required by distributed models and by stakeholders, such as depicted within the downscaled RegIS socio-economic scenarios, should not be under-estimated. Although they are only illustrative and deliberately intended to demonstrate the potential for divergent futures and associated changes, the speculative (but necessarily precise given the need for quantification) nature of the downscaled scenarios means they are contentious and inevitably subject to some disagreement. As suggested by Parson et al. (2003), significant time 
resources are specifically required to convey the meaning, basis and limits of the scenarios. In addition, the level of spatial detail can render them, in the eyes of some local stakeholders, as unacceptable portrayals of future development. For example, the Regional Enterprise scenario for East Anglia contained significant urban development along the North Norfolk coast due to a desire to have second homes in this affluent scenario within this scenically attractive area. However, it was considered by a number of stakeholders that this would not be allowed to happen under any circumstances. If we had shown the 'same' scenario (in terms of overall numbers of new homes within the region) at a lower level of spatial resolution, such strong opposition is less likely to have emerged. What is an appropriate level of spatial detail in a scenario to facilitate informed dialogue, whilst avoiding instantaneous rejection, will depend upon the stakeholder and the specific context, e.g. the institutional history surrounding resource management and development of a particular locale.

Furthermore, it was necessary to develop an additional 'Planners' Scenario' for urbanization based on discussions with planning officers in the two regions who felt that the RegIS socio-economic scenarios were 'extremes' between which the future would lie, and that the scenario projections for 2050 did not relate well to the changes envisaged within the Planners 15 year cycle of the structural planning process. The 'Planners' Scenario' is effectively a 'preferred' scenario on the part of regional planners, given the context of current trends and changes ('dynamics as usual'). The scenario was based on the reinforcement of current trends for housing commitments within pre-existing regional planning guidance and economic strategies. These commitments are location specific but are not necessarily a guide to the future type of permitted development (in terms of density for example) or the extent of future development. Such misconceptions of the role of scenarios can prolong the stakeholder dialogue process needed to develop agreement, or can indeed prevent agreement. Neverthessless, unlike in some other studies (e.g Parson et al., 2003), RegIS has demonstrated that the development of such quantified local scenarios, and their use in numerical impact models can be successful.

\subsection{The capacity of models to represent complex systems}

Regional climate impact assessments will always be dependent on the models that are the basic building blocks of such studies. The need for regional assessments to produce more detailed output, compared to global assessments, requires that the models used are better able to deal with and portray spatial and temporal variability. Whilst alternative methodologies exist to examine the impacts of climate change on some landscape processes (e.g. physical experiments or using analogue regions e.g. Berry et al., 2001), mathematical models will remain a central methodology in exploring unknown futures. 
It is very important, however, to recognise the true value and limitations of models, which should not be viewed as tools for 'predicting' the future within global change studies. They are, at a fundamental level, experiments that can be used to test our perceptions of how the future might evolve. The linking of quantified socio-economic scenarios with numerical modelling in RegIS highlighted this important distinction between making predictions from [uncertain] futures and exploring the future. It is at this level of testing our perceptions of how the future might evolve that such models fulfil both the needs of stakeholders for guidance as to future change and also the basic needs of scientific research to develop, test and revise hypotheses, where the model is a formal characterisation of those hypotheses. Therefore, models, like hypotheses, are dynamic and evolve in response to the improving understanding of a system.

To tackle the spatial complexity of the environment and the range of processes operating within this environment requires a suite of different modelling approaches. A model that is appropriate for the description of physical processes will not necessarily be appropriate for processes of human decisionmaking. The RegIS modelling methodology was based on a range of contrasting modelling techniques (expert judgement, statistical approaches, optimisation models and process-based models) and timesteps (daily, weekly and long-term average). This use of multiple modelling techniques is a strength of the RegIS methodology and not a weakness.

It is evident that the success of regional studies is a function of the capacity of models to represent multi-sectoral, regional-scale processes. Can existing models adequately represent current conditions and future changes at a regional scale? The answer to this question from the RegIS experience seems inevitably to be partly (supporting the results of Lambin et al., 2000). Such models can always be improved upon, but it is clear that the technical advancement of integrating models also requires the practical experiences gained from projects such as RegIS. An important challenge for any regional integrated assessment is the integration of these different approaches and temporal resolutions into a common modelling framework and within a consistent modelling paradigm. The RegIS project has demonstrated that successful integration requires that the complexity should be in the level of integration rather than the sectoral processes, which can be represented by simplified sectoral models (i.e. meta-models) to facilitate the multiple model runs needed for IA. Such models may not be 'stateof-the-art', but integrated within an IAM they will provide new insights and possible future developments that sectoral models cannot provide.

\subsection{Error propagation}


The dependency of integrated assessments on the linkage of models and the flow of numerical information between different sectoral models engenders integrated assessments with the potential for significant error propagation. Validation of an integrated assessment methodology as a whole is not possible, as the requisite data are not usually available (Dowlatabadi, 1995). Such error propagation can potentially create unexpected anomalies in the results from a part of the regional system that occurs at the end of the chain of data exchange which will only partly be addressed by ensuring that impact models are calibrated and validated within the integrated assessment methodology (Dowlatabadi, 1995), rather than independently outside of it.

Because of the large number of individual simulations performed within a single IA, due to the combinations of climate, soil and land use, it is feasible that the Law of Large Numbers would prevent significant error propagation within the linked models. This mathematical theorem states that in repeated, independent trials with the same probability of success in each trial, the chance that the percentage of successes differs from the probability by more than a fixed positive amount converges to zero as the number of trials goes to infinity. So whilst in a small sample the actual results may vary considerably from predicted results, as the samples increases to infinity the calculated probability becomes extremely accurate. However, although the chance of a large difference between the percentage of successes and the chance of success gets smaller and smaller as $n$ grows, nothing prevents the difference from being large in some sequences of trials. So in a regional study in which outputs are being presented spatially at a sub-regional scale, as in RegIS, it is quite feasible in some areas for the simulations to diverge due to error propagation. The Law of Large Numbers will only limit error propagation in a regional IA if there are many simulations (for example, if the unit of simulation is much smaller than the region or if stochastic modelling is employed) but the results are aggregated up to a scale that provides the large number.

Within the reported study, the hydrological results are very important in terms of the mechanisms of the linked modelling framework, because the sector is at the end of the flow of quantitative information (starting from the socio-economic and climate scenarios, through the coastal and river flooding modelling and finally through the land use modelling). The output of summed drainage and runoff from the crop growth model, area-weighted by the results of the farm model form the principle input to the hydrological model. A statistical analysis of the differences between the hydrological results from the scenarios and the baseline, in comparison with the results from the other models was performed to assess any significant problems with error propagation.

Two statistical tests were performed to examine the changes in model output associated with the scenarios. These were a paired t-test, which computes the difference between each grid square of the compared scenarios and tests if the average differs significantly from 0 , and the Pearson correlation 
coefficient which is a measure of the degree of association between the distributions of the values being compared. The paired t-test is a test on the regional means that compares the different scenarios in a global way, whilst the Pearson correlation coefficients, which vary between -1 and +1 , indicate either negative or positive linear relationships, respectively. A value of 0 indicates that neither of the two scenarios can be predicted from the other using a linear equation. A value of 1 indicates a perfect match.

The Pearson correlation coefficients between the scenarios for the hydrological variables were always very high (near to 1.0) even though there are often statistically significant differences between the scenarios at the level of the regional means (i.e. the t-tests). This suggests that the pattern of the spatial changes in the hydrological variables that occur between the scenarios are either constant or are a function of the original baseline values. This is in contrast to the results for the land use model. The implication of this observation is that the hydrological results are more firmly dependent on the (unchanging) landscape characteristics of the regions, than are the land use results. Thus, in general terms it seems that the hydrological model is more sensitive to the physical properties of the landscape (consistent with Boorman et al., 1995) and to the climatic change (as also reported by Evans \& Schreider, 2002) and relatively less sensitive to the socio-economic-induced land use changes (urbanization, woodland creation, agricultural change), in comparison with the land use model which is most sensitive to the socio-economic scenarios. Whilst it is not possible to draw definite conclusions from this observation, it would seem reasonable to suggest that error propagation (i.e. resulting from the land use change inputs) has not unduly affected the hydrological results. In future studies, more attention needs to be given to understanding error propagation in linked modelling systems. This will require the development of IAM's which allow many more simulations than were possible in RegIS. Once error propagation in linked modelling systems is better understood, the resulting implications for output uncertainty need to be effectively communicated to the relevant stakeholders.

\subsection{Model transparency and transportability}

As discussed, the study of complex systems often gives rise to the construction of complex models. The benefit of integrating models to describe complex systems is that a much wider range of processes and process interactions can be considered, including effects and impacts of interacting multiple pressures which are difficult to analyse in any other way. This inevitably means, however, that it is difficult to identify a single factor that creates a certain result: in many cases several interacting processes will have contributed to the same result. The lack of a clear link between cause and effect in such complex modelling systems introduces the problem of transparency in 
understanding the model results. For example, if there is a change in the water resources of one catchment compared to another, stakeholders expect that it should be possible to determine the cause. Was it due to a shift in production of a crop on sandy soils, which was associated with a change in the subsidy or a change in the autumn cultivation period, or some combination of factors? In order for the results of IA's to be credible to stakeholders it is fundamental that the IAM is constructed in such a way that (multiple) cause and effect relationships can be identified, and ensuing results from the IA explained. This will inevitably require a modelling system which allows the user to interact with, and explore, the system through many simulations.

This point of transparency being a precursor for credibility in the eyes of stakeholders is also relevant to the construction and application of scenarios. The climate change scenarios used in RegIS are much less transparent to stakeholders than the regional socio-economic scenarios, due to their underpinning assumptions and the complex nature of GCM's. The socio-economic assumptions that form the basis of the SRES emissions scenarios refer to the global scale and large-scale regions of the world, e.g. N America, China, Africa, etc, and make no reference to national or sub-national differences or heterogeneity. There is therefore no apparent direct link between the socio-economic futures at the scale of stakeholder interests and the scale of the futures associated with the emissions scenarios. Although the linking of socio-economic scenarios (RegIS regional socio-economic scenarios within UKCIP national economic scenario within SRES international scenarios) used within RegIS helped to provide a coherent framework for increasing resolution, it does not provide a means to place the region within the global context of the emissions scenario.

Furthermore, the translation of emissions into variables of climate change is based on the use of complex models of the global climate system (GCMs), the mechanisms of which are not open to understanding by a non-expert. It is not possible for a non-expert to understand the quantitative link between carbon dioxide emissions and regional climate change and to make an objective assessment of the risks of climate change, due to the opaque workings of GCM's and the multiple effects of aerosols, dust particles, oceanic circulations and thermal stores etc. They are required to subjectively accept (or not) the model predictions.

Conversely, the regional socio-economic scenarios in the RegIS study are transparent, in that the assumptions underpinning the description and quantification of each storyline are explicit. The model results can be viewed, therefore, in light of these assumptions. In order to increase the transparency of the RegIS outputs further, the scenarios applied in the RegIS study were based not only on integrated (internally-consistent) visions of the future, but also on the disaggregation of these scenarios into their constituent climate and socio-economic parts. Compared to modelling studies using a 'co-evolutionary' scenario approach, this has allowed a comparison of the relative sensitivity 
of the key impacts to variation in climate and socio-economic conditions, and to interactions between them (as recommended by Parson et al. 2003).

\subsection{Adaptation issues}

The final stage of the DPSIR framework that has guided the RegIS analysis is the 'response' to environmental impacts. Response refers to the capacity of people and societies to adapt to specific changes in the state of a system. In terms of the IPCC guidelines for climate impact assessment (Carter et al., 1994; Parry and Carter, 1998) these adaptation responses are of two general types: autonomous adaptation (e.g. the spontaneous responses and decisions of natural systems, individuals and organisations to change their day-to-day actions or management in response to changing circumstances) and policy implementation (e.g. the political decision to regulate against an adverse outcome or to support certain development pathways).

The RegIS methodology directly addresses both of these forms of adaptation. Autonomous adaptation is implicit to several of the sectoral models and thus, is included directly in the model outputs in response to the different scenarios. For example, the model of changing land use is based on farmer decisions, and how these decisions will have changed, given new set of climatic and techno-economic conditions. The model of species' distributions indicates how an organism will need to disperse in response to its changing environment. In each of these cases, however, RegIS has identified the need to determine whether the proposed autonomous adaptation options are possible in practice, but has not been able to model the actual response. So does the need for capital investment create a barrier to land use change? Can individual species disperse from their current to potential new distributions sufficiently rapidly?

No adaptation options were explicitly modelled in the present RegIS modelling. However RegIS did examine the consequences of the different socio-economic scenarios that were based on alternative visions of future socio-economic and policy pathways. In particular the two selected socio-economic storylines (Regional Enterprise and Global Sustainability) incorporate very different roles for the scope and influence of policy upon the key drivers and pressures which results in socio-economic change and its subsequent influence upon the management of natural resources as shown in Table 3. Hence, the policy maker can compare the influence of climate change upon natural resources arising from a governance framework that is more focused upon a conventional growth paradigm with one that is more focused upon achieving sustainable development globally. 
In future studies, more attention is being given to evaluating stakeholder-selected policy choices in an iterative and interactive manner, and to explicitly include adaptation to climate change within the socio-economic scenarios. The potential effectiveness of adaptation options to climate change could then be gauged through direct comparison with results from the baseline socio-economic scenario with the climate change scenarios.

\subsection{Next Steps}

The key lesson learnt from RegIS was that credibility of the results of the IA in the eyes of stakeholders was limited by the lack of model simulations. This arose from the complexity of the sectoral models and resulted in a lack of transparency regarding explanations of the relative importance of multiple stresses to the results, and the limited means of assessing uncertainty.

Although the RegIS project was successful in demonstrating the importance of cross-sectoral impacts, the wider use of the methodology by the stakeholder community has been hindered by the complexity of the models used. Although the development of the methodology was stakeholder-led, the application of the methodology was not. The RegIS methodology remained as a scientific, rather than an interactive framework.

Following a review of the RegIS project at a UKCIP-hosted technical workshop for stakeholders, the need to simplify the modelling component to enable greater model linkage, feedbacks, model runs and stakeholder interaction was identified. A follow-on project (RegIS2) seeks to address these needs. RegIS2 is developing, with stakeholders, the use of computationally simpler and faster modelling techniques, so called 'meta-models', within a robust user friendly interface to make the RegIS methodology available to the wider stakeholder community. Stakeholders are working with the researchers to identify and assess key regional issues, risks, uncertainties and potential responses, as recommended by Parson et al. (2003).

\section{$5 \quad$ Conclusions}

The 'Regional Climate Change Impact and Response Studies in East Anglia and North West England' (RegIS) is the first regional integrated assessment study in the UK. RegIS has developed a research methodology for stakeholder-led, regional climate change impact assessment which serves the desires of a diverse range of policy makers and stakeholders in the UK for assessments of the potential local impacts of global change. It focuses on the major sectors driving landscape change (agriculture, biodiversity, coastal and river zones and water resources) about which stakeholders had 
previously raised concerns and produced policy-relevant information that can be used at regional and local scales.

Integrated assessments are needed to understand these complex systems, including process interactions across a range of scales and sectors. Thus, integrated assessments will provide new insights which will compliment those derived by more detailed sectoral assessments. Fundamental methodological issues have been raised by RegIS which reflect the difficulty of multi-sectoral modelling studies at local scales. In particular, the role of scenarios, error propagation in linked models, model validity, transparency and transportability as well as the use of integrated assessment to evaluate adaptation options to climate change are examined. RegIS has demonstrated that, although there is the risk that the development of local socio-economic determinands of particular impacts at the local scale is a highly complex and potentially indefensibly arbitrary exercise (Parson et al. 2003), the continual effort of stakeholder engagement can render sufficient credibility to the resulting scenarios to provide far more defensible results than implicitly or explicitly assuming that the present socio-economic conditions will continue unchanged.

There is no doubt that the scientific community has in recent years made considerable progress in advancing integrated assessment methodologies, but it is also clear that a lot still has to be learnt. The value, therefore, in studies such as RegIS is the understanding that can be generated from the model experiments and it is this understanding that future regional studies should seek to advance.

\section{Acknowledgements}

RegIS was funded by the Department of Environment, Food and Rural Affairs (Project No. CC0337) and the UK Water Industries Research within the UK Climate Impacts Programme. Contributions in kind were also provided to the project by the Environment Agency and English Nature.

The RegIS partners are extremely grateful to the large number of stakeholders who freely gave of their time and expertise during the course of the project. The important contributions of Prof. Peter Loveland (project co-ordinator), Diana Wilkins (DEFRA project manager) and Dr Merylyn McKenzie Hedger (former Head of UKCIP) to the success of RegIS are gratefully acknowledged.

Finally the contributions of Janet Annetts, Kerry Pearn and Anton De Baets (Silsoe Research Institute), Terence Dawson and Richard Pearson (Environmental Change Institute, University of Oxford), Theresa Wilson (Flood Hazard Research Centre, Middlesex University), Robert Wood (University of Manchester), Patricia Bellamy and Pablo Navarro (Cranfield University), Isabelle 
Reginster (Université catholique de Louvain) and George Cojocaru (Research Institute for Soil Science and Agrochemistry, Romanian Academy of Sciences) are gratefully acknowledged.

\section{$7 \quad$ References}

Abler, D.G. and Shortle, J.S.: 2000. Climate change and agriculture in the Mid-Atlantic Region. Climate Res. 14(3), 185-194.

Alcamo, J., Leemans, R. and Kreileman, E. (eds.): 1998. Global Change Scenarios of the $21^{s t}$ Century: Resultsw from the IMAGE 2.1 Model. Elsevier, Oxford, UK.

Alcamo, J., Kreileman, G.J.J., Bollen, J.C., vanden Born, G.J., Gerlagh, R., Krol, M.S., Toet, A.M.C., and deVries, H.J.M.: 1996. Baseline scenarios of global environmental change. Global Environmental Change-Human and Policy Dimensions 6 (4), 261-303.

Annetts, J.E. and Audsley, E.: 2002. Multiple objective linear programming for environmental farm planning. J. Operational Research Society 53, 933-943.

Arnell, N.: 1998. Climate change and water resources in Britain. Climatic Change, 39, 83-110.

Arnell , N.W., M.J.L. Livermore, S. Kovats, P. Levy, R. Nicholls, M.L.Parry \& S. Gaffin, 2004. Climate and socio-economic scenarios for climate change impacts assessments: characterising the SRES storylines. Global Environmental Change, in press.

Berkhout, F., Hertin, J. and Jordan, A.: 2002. Socio-economic futures in climate change impacts assessment: using scenarios as learning machines. Global Environmental Change, 12, 83-95.

Berry, P.M., Dawson, T.P., Harrison, P.A, Pearson, R.G. and Butt, N.: 2003. The sensitivity and vulnerability of terrestrial habitats and species in Britain and Ireland to climate change. Journal for Nature Conservation, 11, 15-23.

Berry, P.M., Dawson, T.P, Harrison, P, A. and Pearson, R.: 2001. 'Impacts of climate change and the implications for conservation' in Bradley, P. (ed), Exotic and Invasive species: should we be concerned? Proceedings of the $11^{\text {th }}$ Conference of the Institute of Ecology and Environmental Management. $6^{\text {th }}$ April 2000, pp.78-82.

Bijl, W., Flather, R., de Ronde, J.G., Schmith, T.: 1999. Changing storminess? An analysis of longterm sea level data sets. Clim. Res. 11(2), 161-172

Boorman, D.B., Hollis, J.M. and Lilly, A.: 1995. Hydrology of Soil Types: A Hydrologically based classification of the soils of the UK. Institute of Hydrology Report No. 126, Wallingford, UK, p. 137.

Brown, C.D., Bellamy, P.H., and Dubus, I.G.: 2002. Prediction of pesticide concentrations found in rivers in the UK. Pest. Manag. Sci. 58 (4), 363-373. 
Carretero, J.C., Gomez, M., Lozano, I., de Elvira, A.R., Serrano, O., Iden, K., Reistad, M., Reichardt, H., Kharin, V., Stolley, M., von Storch, H., Gunther, H., Pfizenmayer, A., Rosethal, W., Stawarz, M., Schmith, T., Kaas, E., Li, T., Alexandersson, H., Beersma, J., Bouws, E., Komen, G., Rider, K., Flather, R., Smith, J., Bijl, W., de Ronde, J., Mietus, M., Bauer, E., Schmidt, H., Langenberg, H.: 1998. Changing waves and storms in the northeast Atlantic? Bull. Amer. Meteorol. Soc. 79 (5), $741-760$

Carter, T.R., Parry, M.L., Harasawa, H. and Nishioka, S.: 1994. Technical guidelines for assessing climate change impacts and adaptations with a summary for policy makers and a technical summary. Department of Geography, University College London, UK and the Centre for Global Environmental Research, National Institute for Environmental Studies, Japan. Available from IPCC Secretariat.

Cash, D.W. and Moser, S.C.: 2000. Linking global and local scales: designing dynamic assessment and management processes. Global Environmental Change 10, 109-120.

Cohen, J.: 1960. A coefficient of agreement for nominal scales. Educational and Psychological Measurement, 20, 37-46.

Conway, D., Krol, M., Alcamo, J., and Hulme, M.: 1996. Future availability of water in Egypt: The interaction of global, regional, and basin scale driving forces in the Nile Basin. Ambio 25 (5), 336342.

Dowlatabadi, H.: 1995. Integrated assessment models of climate change: An incomplete overview. Energy Policy 23(4/5), 289-296.

Downing, T.E., Harrison, P.A., Butterfield R.E., and Lonsdale, K.G. (eds.): 2000. Climate Change, Climatic Variability and Agriculture in Europe: An Integrated Assessment. Research Report No. 21, Environmental Change Institute, University of Oxford, p. 446.

Downing, T.E., Ringius, L., Hulme, M. and Waughray, D.: 1997. Adapting to climate change in Africa. Mitigation and Adaptation Strategies for Global Change, 2, 19-44.

Easterling, W.E.: 1997. Why regional studies are needed in the development of fullscale integrated assessment modelling of global change processes. Global Environmental Change 7(4), 337-356.

European Environment Agency: 1998. Europe's Environment: The Second Assessment. Elsevier Science Ltd., Oxford, p. 293

Evans, J. and Schreider, S.: 2002. Hydrological impacts of climate change on inflows to Perth, Australia. Climatic Change, 55, 361-393.

Fisher, A.: 2000. Preliminary findings from the Mid-Atlantic Regional Assessment. Climatic Research 14(3), 261-269.

French, P.W.: 2001. Coastal defences: Processes, Problems and Solutions. Routledge, London, p 384. Halcrow Maritime, HR Wallingford and Flood Hazard Research Centre (2000). National appraisal of 
assets at risk from flooding and coastal erosion. Report to MAFF.

Handmer, J., Dovers, S. and Downing, T.E.: 1999. Societal Vulnerability to Climate Change and Variability. Mitigation and adaptation strategies for global change, 4, 267-281.

Harremoes, P., and Turner, R.K.: 2001. Methods for integrated assessment. Regional Environment change 2, 57-65.

Harrison, P.A., Vanhinsbergh, D.P., Fuller, R.J. and Berry, P.M.: 2003. Modelling climate change impacts on the distribution of breeding birds in Britain and Ireland. Journal for Nature Conservation, 11, 31-42.

Holman, I.P., Nicholls, R.J., Berry, P.M., Harrison, P.A., Audsley, E., Shackley, S., Rounsevell, M.D.A.: Submitted. A regional, multi-sectoral and integrated assessment of the impacts of climate and socio-economic change in the UK: II Results. Climatic Change

Holman, I.P., Loveland, P.J., Nicholls, R.J., Shackley, S., Berry, P.M., Rounsevell, M.D.A., Audsley, E., Harrison, P.A., and Wood, R.: 2001. RegIS - Regional Climate Change Impact Response Studies in East Anglia and North West England. DEFRA, London, p.20, (available from www.ukcip.org.uk).

Holman, I.P. and Loveland, P.J. (eds.): 2001. Regional Climate Change Impacts in East Anglia and the North West (the RegIS project). Final report of MAFF Project No. CC0337 (available from www.ukcip.org.uk).

Holman, I.P., Loveland, P.J. and Najarro, P., 2001: 'Integrated Impacts on Water' in Holman, I.P. and Loveland, P.J. (eds.): 2001. Regional Climate Change Impacts in East Anglia and the North West (the RegIS project). Final report of MAFF Project No. CC0337 (available from www.ukcip.org.uk).

Hollis, J.M. and Brown, C.D.: 1996. 'A catchment-scale model for pesticides in surface water' in Del Re, A.A.M., Capri,E., Evans, S.P. and Trevisan, M.(eds). The environmental fate of Xenobiotics. Proceeding of the X Symposium Pesticide Chemistry, Piacenze, Italy. Pp. 371-379.

Hulme, M. and Jenkins, G.J.: 1998. Climate Change Scenarios for the United Kingdom: Scientific Report. UK Climate Impacts Programme Technical Report No. 1, Climatic Research Unit, Norwich, p. 80.

IPCC: 1996. Climate Change 1995: Economic and Social Dimensions of Climate Change, Contribution of Working Group III. Cambridge University Press, New York, pp. 367-396.

IPCC: 2001a. Climate Change 2001: The Scientific Basis. Contribution of Working Group I to the Third Assessment Report of the Intergovernment Panel on Climate Change. Cambridge University Press, New York, p. 944 
IPCC: 2001b. Technical Summary. Climate change 2001: Impacts, Adaptation, and Vulnerability. A Report of Working Group II of Intergovernmental Panel on Climate Change Cambridge University Press, New York, p. 1000.

Johns, T.C., Carnell, R.E., Crossley, J.F., Gregory, J.M., Mitchell, J.F.B., Senior, C.A., Tett, S.F.B. and Wood, R.A.: 1997. The second Hadley Centre coupled ocean-atmosphere GCM: Model description, spinup and validation. Clim. Dynam. 13 (2), 103-134.

Johnston, T., and Chiotti, Q.: 2000. Climate change and the adaptability of agriculture: A review. $J$. Air Waste Manage. 50 (4), 563-569.

Jones, R.N.: 2001. An environmental risk assessment/management framework for climate change impact assessments. Natural Hazards 23 (2-3), 197-230.

Lambin, E.F., Rounsevell, M.D.A., and Geist, H.J.: 2000. Are agricultural land-use models able to predict changes in land-use intensity? Agriculture Ecosystems and Environment 82 (1-3), 321-331 Sp. Iss.

Lorenzoni, I., Jordan, A., Hulme, M., Turner, R.K., and O'Riordan, T.: 2000: A co-evolutionary approach to climate change impact assessment: Part I. Integrating socio-economic and climate change scenarios. Global Environmental Change, 10, 57-68.

Leemans R: 1999. Modelling for species and habitats: new opportunities for problem solving. Science Of The Total Environment 240 (1-3), 51-73.

Leggett, J., Pepper, W., Swart, R.J., Edmonds, J., Meira Filho, L.G., Mintzer, I., Wang, M.X. and Watson, J.: 1992. Emissions scenarios for the IPCC: An Update. In xxxxxxxx Climate Change 1992: The Supplementary Report to the IPCC Scientific Assessment. Cambridge University Press, Cambridge UK, pp 75-95.

Matsuoka, Y., Morita, T., and Kainuma, M.: 2001. 'Integrated Assessment Model of Climate Change: The AIM Approach' in: Matsuno, T. and Kida, H. (eds.) Present and Future of Modelling Global Environmental Change: Toward Integrated Modeling. Terra Scientific Publishing Company, Tokyo, pp. 339-361.

Miles, E.L., Snover, A.K., Hamlet, A.F., Callahan, B., and Fluharty, D.: 2000. Pacific Northwest Regional Assessment: The impacts of climate variability and climate change on the water resources of the Columbia River Basin. J. American Water Resources Association 36, 399-420.

Ministry of Agriculture, Fisheries and Food: 1999. Flood and Coastal Defence Project Appraisal Guidance. MAFF flood and Coastal Defence Division, London.

Mitchell, J.F.B., and Johns, T.C.: 1997. On modification of global warming by sulfate aerosols. $J$ Climate 10 (2), 245-267.

Morris J.:2003. Economic and Financial Appraisal of Flood Defence for Agriculture, Chapter 9, in Penning-Rowsell E., Johnson C., Tunstall S., Tapsell S., Morris J., Chatterton J., Coker A. and 
Green C., (eds.) The Benefits of Flood and Coastal Defence. Flood Hazard Research Centre, Middlesex University.

Nakicenovic, N. and Swart, R. (eds.): 2000. Special Report on Emissions Scenarios. A Special report of Working Group III of the Intergovernmental Panel on Climate Change. Intergovernmental Panel on Climate Change, Cambridge University Press Cambridge, p. 599.

Nicholls R.J. and Wilson T.: 2001. 'Integrated impacts on coastal areas and river flooding.' in Holman, I.P. and Loveland, P.J. (eds.), Regional Climate Change Impacts in East Anglia and the North West (the RegIS project). Final report of MAFF Project No. CC0337 (available from www.ukcip.org.uk).

Nicholls, R.J. and Mimura, N.: 1998. Regional issues raised by sea-level rise and their policy implications. Climate Research 11, 5-18.

Nicholls, R.J.: 2002a. 'Rising sea levels: potential impacts and responses' in: Hester, R. and Harrison, R.M. (ed.), Global Environmental Change. Issues in Environmental Science and Technology, Number 17, Royal Society of Chemistry, Cambridge, pp. 83-107.

Nicholls, R.J.: 2002b. 'Coastal Change in East Anglia: Results from the RegIS Project' in Gill, J., O'Riordan, T. and Watkinson, A. (eds.), Redesigning the Coast. Tyndall Centre and CSERGE, University of East Anglia, pp. 26-37. (downloadable at http://www.tyndall.ac.uk/research/theme4/theme4_workshops.shtml)

Nordhaus, W.D. and Yang, Z: 1996. RICE: a Regional Dynamic General Equilibrium Model of Alternatiuve Climate Change Strategies. Amer. Econ. Rev. 86, 726-741.

Organization of Economic Co-operation and Development: 1993. OECD Core set of indicators for environmental performance review. Environmental Monograph No. 83, OECD, Paris.

Parry, M.L. and Carter, T.R.: 1998. Climate Impact and Adaptation Assessment: A Guide to the IPCC Approach. Earthscan Publications Limited, London, UK, 166 pp.

Parry, M., Arnell, N., Hulme, M., Martens, P., Nicholls, R,. and White, A.: 1999. The global impact of climate change: a new assessment. Global Environmental Change, 9, S1-S2.

Parry, M.L., Hossell, J.E., Jones, P.J., Rehman, T., Tranter, R.B., Marsch, J.S., Rosenzweig, C., Fischer, G., Carson, I.G. and Bunce, R.G.H.: 1996. Integrating global and regional analyses of the effects of climate change: a case study of land use in England and Wales. Climatic Change 32, 185-198.

Parson, E.A., Corell, R.W. Barron, E.J. Burkett, V. Janetos, A. Joyce, L. Karl, T.R. MacCracken, M.C. Melillo, J. Morgan, M.G. Schimel, D.S. and Wilbanks, T.: 2003. Understanding climatic impacts, vulnerabilities, and adaptation in the United States: Building a capacity for assessment. Climatic Change, 57, 9-42 
Parson, E.A. and Granger Morgan, M.: 2000. Chapter 3: Socioeconomic context for climate impact assessment. US National Assessment Synthesis Team Document. Public Comment Draft.

Pearson, R.G., Dawson, T.P., Berry, P.M. and Harrison, P.A.: 2002. SPECIES: a Spatial Evaluation of Climate Impact on the Envelope of Species. Ecological Modelling, 154(3), 289-300.

Peirce, M.: 1998. Computer-Based Models in Integrated Environmental Assessment. European Environment Agency Technical report No. 14. p. 60.

Reynard, N.S., Prudhomme, C. and Crooks, S.M.: 2001. The Flood Characteristics of Large UK Rivers: Potential Effects of Changing Climate and Land Use. Climatic Change 48, 343-359.

Rosenberg, N.J.: 1993. A methodology called 'MINK' for study of Climate Change Impacts and responses on the Regional Scale. Climatic Change 24, 1-2, 1-6.

Rounsevell, M., Loveland, P., Mayr, T., Armstrong, A.,de la Rosa, D., Legros, J.P.,Simota, C. and Sobczuk, H.: 1996. ACCESS: A spatially-distributed soil water and crop development model for climatechange research. Aspects of Applied Biology, 45, 85-92

Rounsevell, M.D.A.: 2000. 'Agriculture and climate change scenarios' in Cramer, W., Doherty, R., Hulme, M., and Viner, D. (eds.), Climate scenarios for agricultural, forest and ecosystem impacts. ECLAT-2 Workshop Report No. 2. Climate Research Unit, Norwich, UK, pp. 21-31.

Rounsevell, M.D.A. Annetts, J.E., Audsley, E. Mayr, T. and Reginster, I. (2003). Modelling the spatial distribution of agricultural land use at the regional scale. Agriculture, Ecosystems and Environment, 95(2-3), 465-479

Science and Policy Associates Inc and ESYS: 1996. Proposal for a UK Integrated Climate Change Impacts Assessment. Report prepared for the Department of the Environment and the Environment Agency. Department of the Environment, London, p. 28.

Senior, C.A., Jones, R.G., Lowe, J.A., Durman, C.F., Hudson, D.: 2002. Predictions of extreme precipitation and sea-level rise under climate change. Philos. Trans. R. Soc. Lond. Ser. A-Math. Phys. Eng. Sci. 360(1796), 1301-1311

Shackley, S. and Deanwood, R.: 2002. Stakeholder perceptions of climate change impacts at the regional scale: Implications for the effectiveness of regional and local responses. Journal of Environmental Planning and Management 45(3), 381-402.

Shackley, S. \& Deanwood, R. (2003), Constructing social futures for climate-change impacts and response studies: building qualitative and quantitative scenarios with the participation of stakeholders. Climate Research, 24 (1), 71-90.

Smit, B., Pilifosova, O., Burton, I., Challenger, B., Huq, S., Klein, R.J.T., and Yohe, G.: 2001 'Adaptation to Climate Change in the Context of Sustainable Development and Equity' in: McCarthy, J.J., Canziani, O.F., Leary, N.A., Dokken, D.J., \& White, K.S. (eds.) Climate Change 
2001: Impacts, Adaptation and Vulnerability. Cambridge University Press, Cambridge, pp. 877912.

Smith, L.P.: 1976. The Agricultural Climate of England and Wales. MAFF Technical Bulletin 35, HMSO, London, p.147

Strzepek K, Yates D, Yohe G, Tol RJS \& Mader N.: 2001. Constructing "not-implausible" climate and economic scenarios for Egypt. Integrated Assessment 2, 139-157

Sykes, M.T. and Haxeltine A.: 1998. 'Modelling the response of vegetation and biodiversity to climate' in Sala, O. and Chapin III, F.S. (eds.) Global Biodiversity: Current Trends and Future Scenarios. Springer-Verlag, Berlin.

Tol, R.S.J.: 1998. 'Socio-economic scenarios' in Feenstra, J.F., Burton, I., Smith, J.B. and Tol, R.S.J. (eds.), Handbook on methods for climate change impact assessment and adaptation strategies. United National Environment Programme and the Institute for Environmental Studies, vrije Universiteit Amsterdam, Netherlands, p. 2-1 - 2-16.

Toth, F.L.: 2003. Climate policy in light of climate science: the ICLIPS project. Climatic Change 56, 7-36.

Tyson, P., Steffen, W., Mitra, A.P., Fu, C., and Lebel, L.: 2001. The earth system: regional - global linkages. Reg. Environ. Change 2, 128-140.

United Kingdom Climate Impacts Programme: 2001. Socio-economic scenarios for climate change impact assessment: a guide to their use in the UK Climate Impacts Programme. UKCIP, Oxford, p. 123.

Warren, R.: 2002. A blueprint for integrated assessment of climate change. Tyndall Centre Technical Report 1, Norwich, p. 20.

Yarnal, B.: 1998. Integrated regional assessment and climate change impacts in river basins. Climate Research 11 (1), 65-74.

Yohe, G., Jacobsen, M. and Gapotchenko, T.: 1999. Spanning "not implausible" futures to assess relative vulnerability to climate change and climate variability. Global Environmental Change $\mathbf{9}$, 233-249

Yohe, G., Strzepek, K., Pau, T. and Yoh,e C.: 2002 Economic analysis and adaptive capacity with reference to an Egyptian case study. Unpublished Manuscript, Wesleyan University, Middletown, CT., USA. 


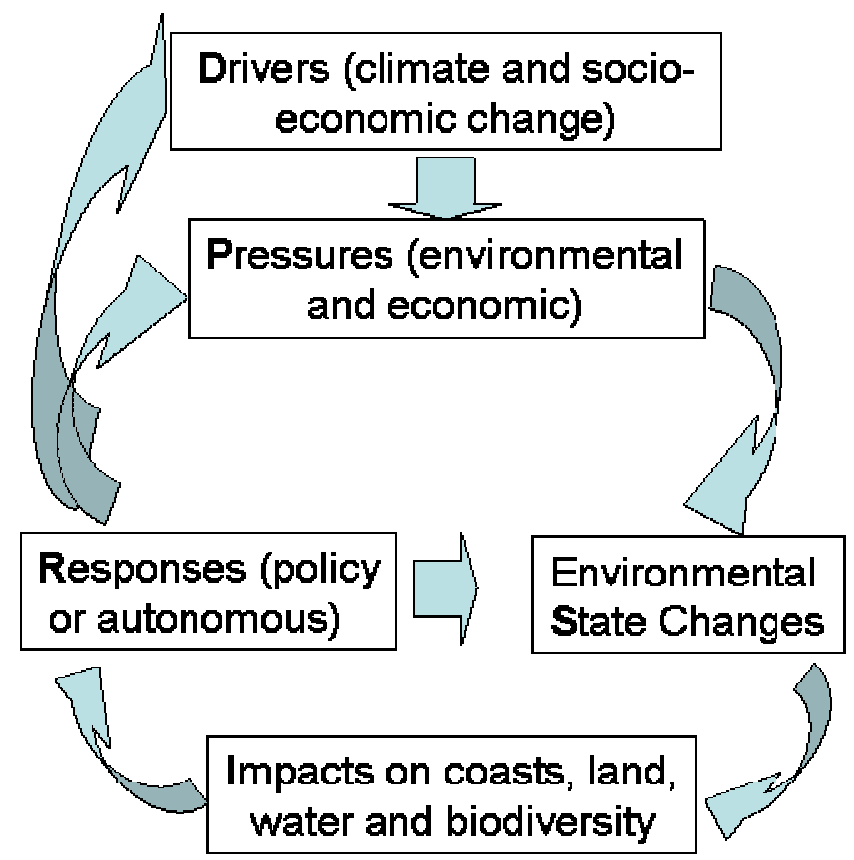

Figure 1: The 'Drivers-Pressure-State-Impact-Response' (DPSIR) framework applied in RegIS 


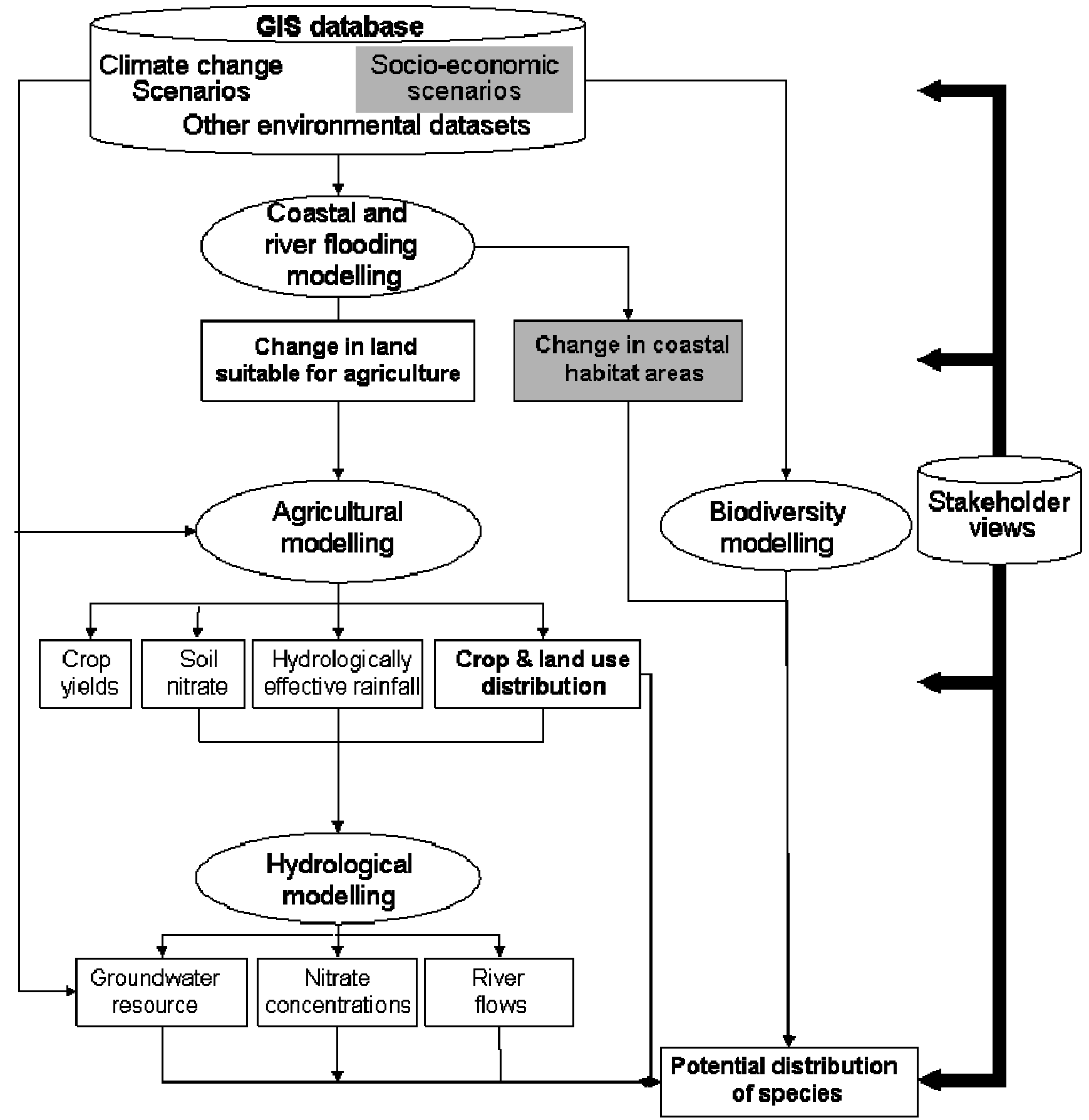

Figure 2: Overview of the RegIS methodology (rectangles represent model outputs; bold text represents autonomous response options and grey shading represents policy responses) 

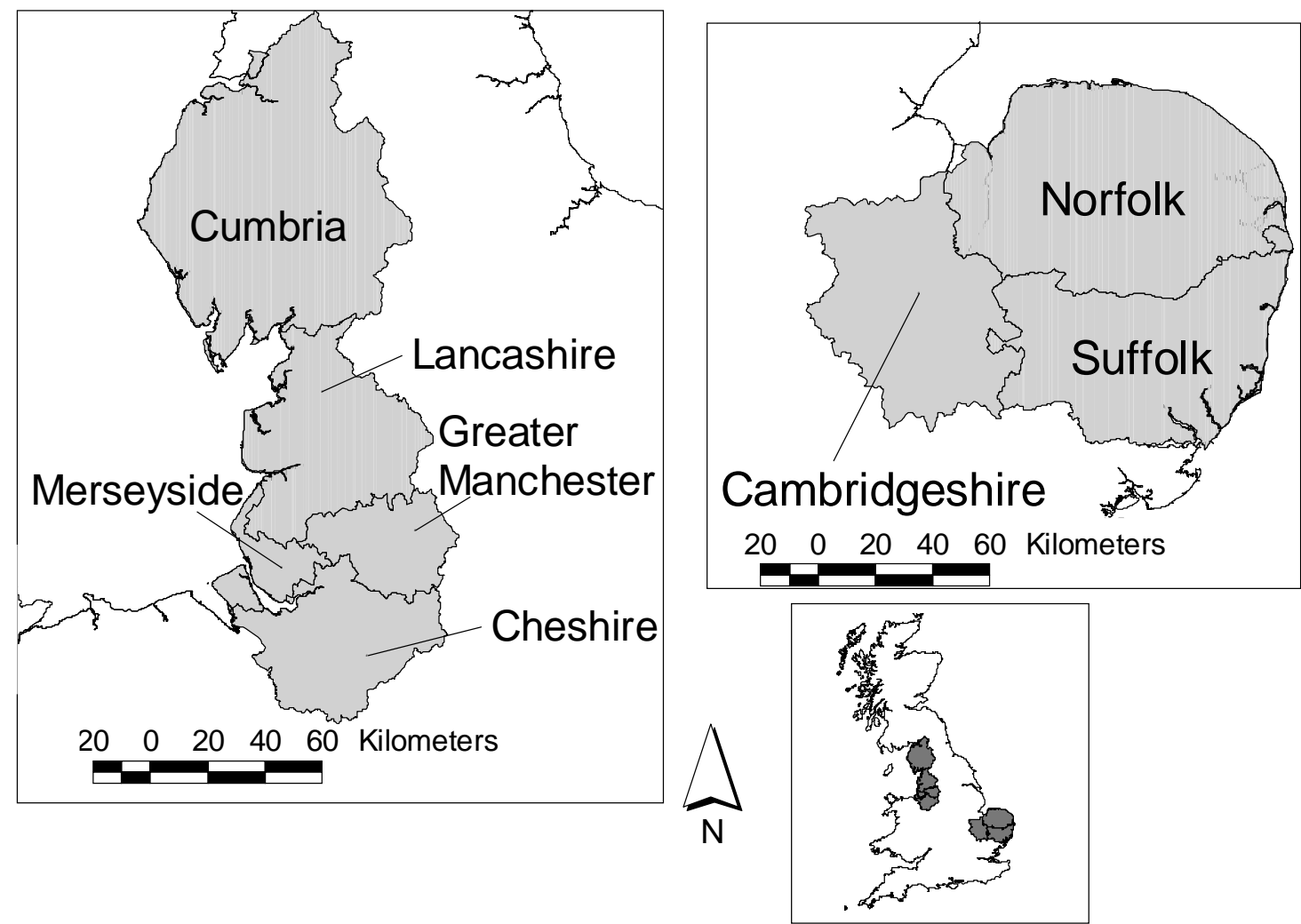

Figure 3: RegIS case study areas: (left) North West and (upper right) East Anglia

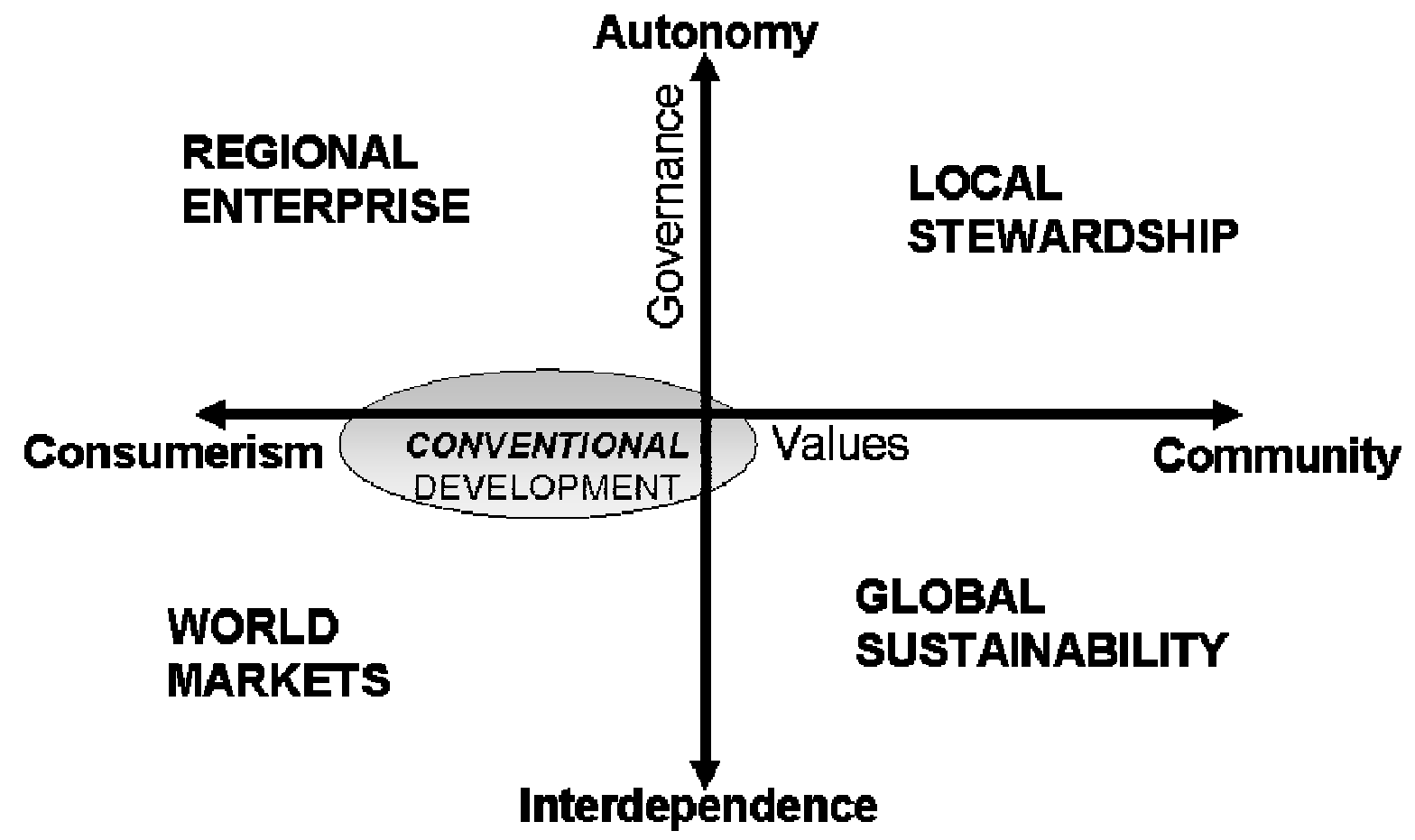

Figure 4: The RegIS socio-economic scenario framework (adapted from UKCIP, 2001) 


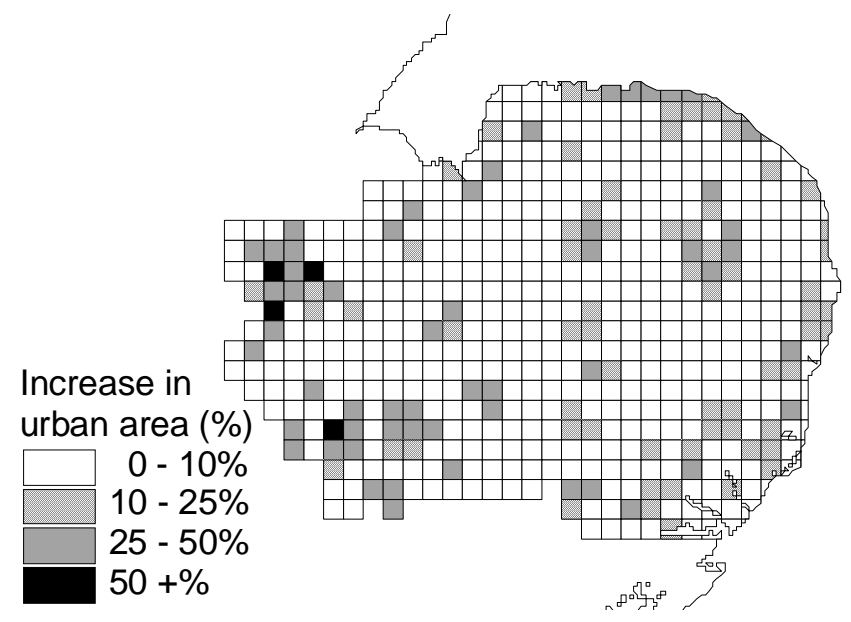

Figure 5: Example of the spatial parameters within the RegIS socio-economic scenarios: percentage change in urban cover in East Anglia under the 2050s Regional Enterprise scenario 
Table 1: Summary of scenario indicators.

\begin{tabular}{|c|c|c|}
\hline Indicator & Spatial Resolution & Use in RegIS \\
\hline \multicolumn{3}{|l|}{ Spatial indicators } \\
\hline$\Delta$ urban areas $(\%)$ & $5 \mathrm{~km} \times 5 \mathrm{~km}$ & $\begin{array}{l}\text { To estimate area available for agriculture } \\
\text { and natural habitats }\end{array}$ \\
\hline$\Delta$ population numbers $(\%)$ & $5 \mathrm{~km} \times 5 \mathrm{~km}$ & To estimate population density \\
\hline$\Delta$ total agricultural area $(\%)$ & $5 \mathrm{~km} \times 5 \mathrm{~km}$ & To define the limits of the farm model runs \\
\hline $\begin{array}{l}\Delta \text { non-agricultural area, e.g. } \\
\text { woodland, amenity }(\%)\end{array}$ & $5 \mathrm{~km} \times 5 \mathrm{~km}$ & To estimate potential habitats \\
\hline $\begin{array}{l}\Delta \text { agri-environment areas, e.g. } \\
\text { Nitrate Vulnerable Zones }(\%)\end{array}$ & $5 \mathrm{~km} \times 5 \mathrm{~km}$ & $\begin{array}{l}\text { To modify the farm model management } \\
\text { inputs }\end{array}$ \\
\hline \multicolumn{3}{|l|}{ Non-spatial indicators } \\
\hline$\Delta$ crop prices $(\%)$ & National & Input to farm model \\
\hline $\begin{array}{l}\Delta \text { crop yields due to technological } \\
\text { advances }(\%),\end{array}$ & National & Input to farm model \\
\hline$\Delta$ chemical usage $(\%$ & National & Input to farm model \\
\hline$\Delta$ machinery size $(\%)$. & National & Input to farm model \\
\hline$\Delta$ setaside $(\%)$ & National & Input to farm model \\
\hline$\Delta$ subsidy $(\%)$ & National & Input to farm model \\
\hline
\end{tabular}


Table 2: Habitats selected for study in East Anglia and North West England.

\begin{tabular}{|c|c|c|}
\hline Interacting sector & East Anglia & North West England \\
\hline Agriculture & $\begin{array}{l}* \text { Lowland heathland } \\
* \text { Cereal field margins }\end{array}$ & $\begin{array}{l}\text { *\#Upland hay meadows } \\
(* \text { Heathland })^{1}\end{array}$ \\
\hline Water & *Fens & $\begin{array}{l}\text { *\#Blanket and lowland raised bogs } \\
\text { (Mosslands) }{ }^{1}\end{array}$ \\
\hline Coastal processes & $\begin{array}{l}* \text { Coastal grazing marsh } \\
(* \text { Salt marsh })^{1}\end{array}$ & $\begin{array}{l}* \text { Salt marsh } \\
\left({ }^{*} \text { Coastal grazing marsh }\right)^{1}\end{array}$ \\
\hline None & & \#*Montane Arctic - Alpine ${ }^{2}$ \\
\hline \multicolumn{3}{|c|}{ \# European Union Habitats Directive habitats. } \\
\hline
\end{tabular}


Table 3: Summary of the policy directions within the RegIS socio-economic scenarios (SES) for each sector

\begin{tabular}{|c|c|c|}
\hline Sector & $\begin{array}{l}\text { Policy directions under Global } \\
\text { Sustainability (RegIS SES) }\end{array}$ & $\begin{array}{l}\text { Policy directions under Regional Enterprise } \\
\text { (RegIS SES) }\end{array}$ \\
\hline \multirow[t]{2}{*}{ Coastline } & $\begin{array}{l}\text { New coastal development is resisted and } \\
\text { the favoured option is consolidation and } \\
\text { better planning of existing developed and } \\
\text { urban sites }\end{array}$ & $\begin{array}{l}\text { Extensive new development increasing assets at } \\
\text { risk }\end{array}$ \\
\hline & $\begin{array}{l}\text { Coastal zone protection is seen from a } \\
\text { national strategic perspective, with } \\
\text { managed realignment widely adopted }\end{array}$ & $\begin{array}{l}\text { Resources available for repair and maintenance, } \\
\text { especially in areas strategically identified for } \\
\text { development }\end{array}$ \\
\hline \multirow[t]{2}{*}{ Agriculture } & $\begin{array}{l}\text { Agriculture is directed towards that } \\
\text { which is most suitable to be grown } \\
\text { locally in the context of a continental } \\
\text { scale landmass }\end{array}$ & $\begin{array}{l}\text { High value of productive land - tendency to } \\
\text { exploit to maximum. }\end{array}$ \\
\hline & $\begin{array}{l}\text { Subsidy payments, and environmental } \\
\text { restrictions and taxation are used to } \\
\text { move agriculture away from } \\
\text { intensification }\end{array}$ & $\begin{array}{l}\text { Agricultural subsidies will be reduced, which will } \\
\text { expose agricultural production to more global } \\
\text { markets }\end{array}$ \\
\hline Biodiversity & $\begin{array}{l}\text { Biodiversity resources - and priorities for } \\
\text { conservation and improvement - are seen } \\
\text { in a broad spatial context, at the } \\
\text { European and global scales, allowing } \\
\text { downgraded protection of some locally } \\
\text { significant biodiversity resources. }\end{array}$ & $\begin{array}{l}\text { Extensive new development putting pressure } \\
\text { upon existing nature conservation sites (but some } \\
\text { high profile sites better protected, e.g. for } \\
\text { tourism). }\end{array}$ \\
\hline \multirow[t]{2}{*}{ Water } & $\begin{array}{l}\text { Water resources are regarded as a } \\
\text { strategic national resource } \\
\text { Demand management and leakage } \\
\text { reduction allow excess water resources to } \\
\text { be exported to needy regions }\end{array}$ & $\begin{array}{l}\text { Extensive development increases demand. } \\
\text { Increasing demand for water offset by stopping } \\
\text { water transfers out of the region, and buying in } \\
\text { more water from other, less prosperous, regions }\end{array}$ \\
\hline & & $\begin{array}{l}\text { Apart from selected locations, wetland habitat } \\
\text { conservation not a high priority. }\end{array}$ \\
\hline
\end{tabular}

